Macedonian Pharmaceutical Bulletin, 66 (Suppl 1) 167 - 168 (2020)

Online ISSN 1857 - 8969

UDC: $616-056.7: 316.62(497.7)$

DOI: 10.33320/maced.pharm.bull.2020.66.03.083

Short communication

\title{
Social aspect as a part of HRQoL in patients with cystic fibrosis in Republic of North Macedonia
}

\author{
Zoran Nakov $^{1}$, Stojka Naceva Fushtikj ${ }^{2}$, Stevce Acevski ${ }^{3}$, Jasmina Tonic Ribarska ${ }^{4}$, \\ Suzana Trajkovic Jolevska ${ }^{4}$ \\ ${ }^{I}$ Novo Nordisk Pharma DOOEL, st. Nikola Kljusev 11, 1000 Skopje, Republic of North Macedonia \\ ${ }^{2}$ University clinic for children diseases, Ss. Cyril and Methodius University, Mother Tereza 17, \\ 1000 Skopje, Republic of North Macedonia \\ ${ }^{3}$ Alakloid AD, blvd. Aleksandar Makedonski 12, 1000 Skopje, Republic of North Macedonia \\ ${ }^{4}$ Faculty of Pharmacy, Ss. Cyril and Methodius University, Mother Tereza 47, \\ 1000 Skopje, Republic of North Macedonia
}

\section{Introduction}

Cystic fibrosis (CF) is a genetic disorder that occurs as a result of mutations in a single gene responsible for synthesis of a protein known as a cystic fibrosis transmembrane conductance regulator (Tsui and Buchwald, 1991). CF is a rare disease and according to available data in 33 EU countries, more than 42000 patients with CF have been registered. In Republic of North Macedonia (RNM), the average number of patients with CF is 110 . Considering the fact that more than 20 patients of the whole population of RNM are affected with $\mathrm{CF}$, this disease is not administratively recognized as a rare disease in our country.

The clinical picture of $\mathrm{CF}$ is dominated by symptoms of impaired functioning of lungs, liver, kidneys and intestine too (Naceva Fushtikj, 2012). The medical treatment of $\mathrm{CF}$ includes inhalation of mucolytic, inhalation of antibiotic, enzyme, vitamin and physical therapy. The limitations that patients experience due to the daily practice of the necessary therapy, inevitable affects their social activity.

The main objective of this study was to assess the current social aspect of patients with $\mathrm{CF}$ in
RNM. The measurement of the social aspect of patients with $\mathrm{CF}$ is important in order to improve their functional capabilities. The social aspect refers to the quantity and quality of social contacts and interactions (Goodman, 1998).

The assessment of the social aspect was conducted as a part of Health-related quality of life (HRQoL), which provide the patient's general subjective perception of the effect of illness and intervention on physical, psychological and social aspects of daily life (EUnetHTA, 2013).

\section{Materials and methods}

The participants included in this research were adults and adolescents older than 13 years. The survey of the patients was conducted by using the Macedonian version of Cystic Fibrosis Questionnaire Revised (CFQ-R) as a diseasespecific HRQoL instrument. The questionnaires were administrated as a self-administered. All involved patients were informed about the study objectives and data confidentiality, and were asked to indicate their agreement to participate.

\footnotetext{
*zona@novonordisk.com
} 
The answers of the questions from HRQoL module were given as a 5 distinct 4-point Likert scales (always/often/sometime/never). The score was ranged between 0 to 100, whereas higher scores representing a better health. The statistical analysis was performed using SPSS statistical software, Student t-test for independent samples, MannWhitney nonparametric test, Kruskal-Wallis ANOVA-post hoc Mann-Whitney test, Pearson test and Spearman test.

\section{Results and discussion}

The HRQoL survey included thirty-one patients (adults and adolescents) and 12 domains of HRQoL (symptoms and health status) were analyzed. Among them there were 20 men and boys (64.52\%) and 11 women and girls (35.48\%). The ethnic structure of the patients was dominated by ethnic Macedonians (23 ethic Macedonians, 5 ethnic Albanians, 1 other and 3 preferred not to respond).

The questions included in the questionnaire intended for assessment of socials aspect of life were connected to the ability of patients for regular social activity on a daily basis.

The Macedonian patients in comparison with Albanian patients reported higher score for social activity, but there was no statistically significant difference. Taking into account the fact that Macedonian and Albanian patients belong to the white race, differences in the manifestation of symptoms of $\mathrm{CF}$, and consequently the impact of the disease on the social aspect is not expected. The male patients scored their social activity $(\mathrm{p}=0.43)$ not significantly higher compared to female patients.

The social activity was reported with the mean score of 49.64. The obtained score for the social activity was the lowest among the other 11 parameters measured with the HRQoL (emotion, vitality, physical condition, respiratory, eating, digestion, weight, body image, treatment burden, health perception and school/work performance).

This finding may be explained with the fact that $70.97 \%$ of the surveyed patients are teens and young adults (between 13 to 25 years of age) when it is normally to exist a negative impact of their medical condition in their self-perception and in the execution of their daily social activities. The negative impact of CF in execution of daily patient's social activities was also reported by Gee et al. (2003). Low score for social aspect was also obtained in our previous reported study for the
HRQoL in pediatric patients in RNM (Nakov et al., 2019).

\section{Conclusion}

The lowest scores for social activities among other 11 investigated parameters shows that this medical condition has a negative impact on the patients' self-perception and in the execution of their daily social activities.

The adherence of the patients to the regular $\mathrm{CF}$ treatment regimens, which include medication and physical therapy and physical activity, is inevitable accomapained with shortness of time for their daily social activities.

This fact is main reason why these patients scores their social life with the lower score.

\section{References}

EUnetHTA - European network for Health Technology Assessment. 2013. Gu0ideline - Endpoints used for relative effectiveness assessment of pharmaceuticals, HEALTH-RELATED QUALITY OF LIFE and UTILITY MEASURES.

Gee, L., Abbott, J., Conway, S., 2003. Quality of life in cystic fibrosis: the impact of gender, general health perceptions and disease severity. Journal of Cystic Fibrosis 2, 206-213.

Goodman, C.S., 1998. Healthcare technology assessment: methods, framework, and role in policy making. The Am. J. Managed Care, Spec No. SP200-14; quiz SP215.

Naceva Fushtikj, S., 2012. From basic defect to disease. Skopje: Sfera print and marketing.

Nakov, Z., Naceva Fushtikj, S., Tonikj-Ribarska, J., Trajkovikj Jovelska, S., 2019. Health-related quality of life of Macedonian families experiencing cystic fibrosis in pediatric practice. Folia Med. 61, 213-222.

Tsui, L.C., Buchwald, M., 1991. Biochemical and molecular genetics of cystic fibrosis. Adv. Hum. Gen. 20, 153-166.

Maced. Pharm. Bull. 66 (Suppl 1) 167 - 168 (2020) 